\title{
A Study on the Impacts of Climate Change on various sectors, with reference to the state of Karnataka
}

\author{
Dr.H.Nagaraj, Associate Professor, St. Joseph's College of Commerce, India. \\ Ms. Nischitha K, Research Scholar, Bengaluru University, India.
}

\begin{abstract}
Climate Change is the defining issue of our time and we are at a defining moment. From shifting weather patterns that threaten food production, to rising sea levels that increase the risk of catastrophic flooding, the impacts of climate change are global in scope and unprecedented in scale. Without drastic action today, adapting to these impacts in the future will be more difficult and costly. India is both a major greenhouse gas emitter and one of the most vulnerable countries in the world to projected climate change. The country is already experiencing changes in climate and the impacts of climate change, including water stress, heat waves and drought, severe storms and flooding, and associated negative consequences on health and livelihoods. With a 1.2 billion but growing population and dependence on agriculture, India probably will be severely impacted by continuing climate change. Karnataka is the second most vulnerable state in India to be impacted by Climate Change as the North Karnataka regions have the arid and driest regions. As a progressive state, Karnataka envisions job oriented, inclusive economic growth. This will require sustainable industrialization and livelihood diversification. However, such a transition is likely to increase the demand for resources and energy significantly. In this, our proposed study will enable us to know the impact of climate change on important sectors like energy and agriculture, which are the backbone of the state's economy.
\end{abstract}

Key Words: Climate change, Energy, Agriculture, Emissions

\section{INTRODUCTION}

Climate Change is the defining issue of our time and we are at a defining moment. From shifting weather patterns that threaten food production, to rising sea levels that increase the risk of catastrophic flooding, the impacts of climate change are global in scope and unprecedented in scale. Without drastic action today, adapting to these impacts in the future will be more difficult and costly. Greenhouse gases occur naturally and are essential to the survival of humans and millions of other living things, by keeping some of the sun's warmth from reflecting back into space and making Earth livable. But after more than a century and a half of industrialization, deforestation, and large scale agriculture, quantities of greenhouse gases in the atmosphere have risen to record levels not seen in three million years. As populations, economies and standards of living grow, so does the cumulative level of greenhouse gas (GHGs) emissions. Global climate change has already had observable effects on the environment. Glaciers have shrunk, ice on rivers and lakes is breaking up earlier, plant and animal ranges have shifted and trees are flowering sooner. Effects that scientists had predicted in the past would result from global climate change are now occurring: loss of sea ice, accelerated sea level rise and longer, more intense heat waves.

According to the IPCC, the extent of climate change effects on individual regions will vary over time and with the ability of different societal and environmental systems to mitigate or adapt to change. The IPCC predicts that increases in global mean temperature of less than 1.8 to 5.4 degrees Fahrenheit (1 to 3 degrees Celsius) above 1990 levels will produce beneficial impacts in some regions and harmful ones in others. Net annual costs will increase over time as global temperatures increase. In its Fifth Assessment Report, the Intergovernmental Panel on Climate Change, a group of 1,300 independent scientific experts from countries all over the world under the auspices of the United Nations, concluded there's a more than 95 percent probability that human activities over the past 50 years have warmed our planet. The industrial activities that our modern civilization depends upon have raised atmospheric carbon dioxide levels from 280 parts per million to 412 parts per million in the last 150 years. The panel also concluded there's a better than 95 percent probability that human-produced greenhouse gases such as carbon dioxide, methane and nitrous oxide have caused much of the observed increase in Earth's temperatures over the past 50 years. 


\section{CLIMATE CHANGE AND INDIA}

India is both a major greenhouse gas emitter and one of the most vulnerable countries in the world to projected climate change. The country is already experiencing changes in climate and the impacts of climate change, including water stress, heat waves and drought, severe storms and flooding, and associated negative consequences on health and livelihoods. With a 1.2 billion but growing population and dependence on agriculture, India probably will be severely impacted by continuing climate change. Global climate projections, given inherent uncertainties, indicate several changes in India's future climate:

The Global Climate Risk Index 2018 examines the extent to which countries have been affected by the impacts of weather-related loss events such as storms, floods and heat waves. The index looked at the most recent data available from 2016 - as well as long-term trends - from 1997 to 2016.

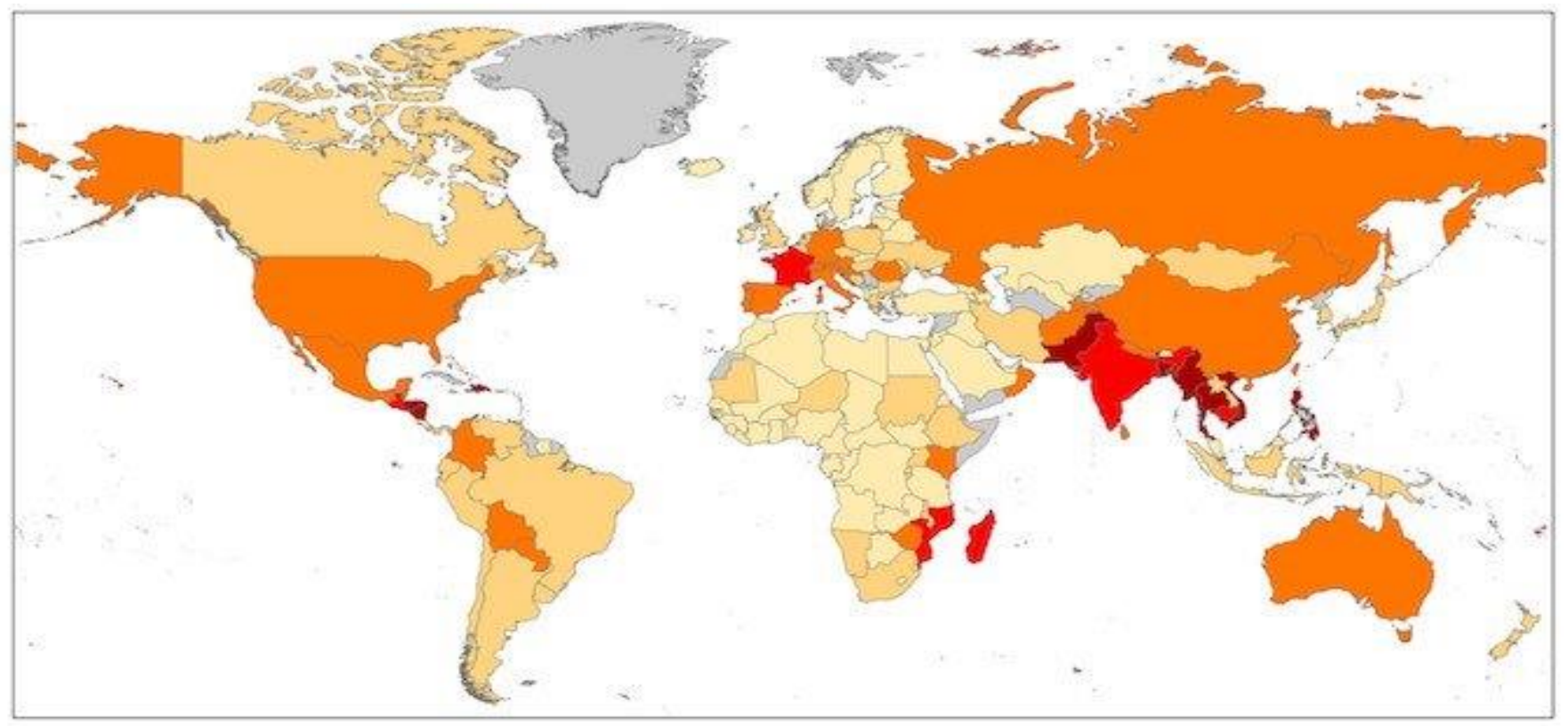

India is already experiencing a warming climate. Unusual and unprecedented spells of hot weather are expected to occur far more frequently and cover much larger areas. Under $4{ }^{\circ} \mathrm{C}$ warming, the west coast and southern India are projected to shift to new, high-temperature climatic regimes with significant impacts on agriculture. A decline in monsoon rainfall since the 1950s has already been observed. The frequency of heavy rainfall events has also increased. A $2^{\circ} \mathrm{C}$ rise in the world's average temperatures will make India's summer monsoon highly unpredictable. At $4{ }^{\circ} \mathrm{C}$ warming, an extremely wet monsoon that currently has a chance of occurring only once in 100 years is projected to occur every 10 years by the end of the century. An abrupt change in the monsoon could precipitate a major crisis, triggering more frequent droughts as well as greater flooding in large parts of India. More than $60 \%$ of India's agriculture is rain-fed, making the country highly dependent on groundwater. Even without climate change, $15 \%$ of India's groundwater resources are overexploited.

India's broad spectrum of highly articulated national policies includes inclusive growth goals in the areas of economic development, human development, and environmental protection. At the national level, India's climate change policies are subsumed in its economicindustrial and human development policies, which come first. Local policies have had some success in limiting significant urban air pollution problems

The broad policy framework on environment and climate change is laid down by the National Environment Policy (NEP) 2006, which promotes sustainable development along with respect for ecological constraints and the imperatives of social justice. The current development paradigm reiterates the focus on sustainable growth and aims to exploit the co-benefits of addressing climate change along with promoting economic growth. The National Action Plan on Climate Change (NAPCC) provides a sharper focus on required interventions. Currently, NAPCC is implemented through eight National Missions, outlining priorities for mitigation and adaptation to combat climate change. The broad policy initiatives of the government are supplemented by actions of the State Governments, Nongovernmental Organizations (NGOs), initiatives of the private sector and other stakeholders. 32 States and Union Territories have put in place the State Action Plan on Climate Change (SAPCC) attempting to mainstream climate change concerns in their planning process. 


\section{KARNATAKA's STAND IN FIGHTING CLIMATE CHANGE}

Karnataka is the second most vulnerable state in India to be impacted by Climate Change as the North Karnataka regions have the arid and driest regions. Flanked by the Arabian Sea, Karnataka is a coastal state in the south west of India. It is the eighth largest state by size and the ninth by population. While the Western Ghats account for a bulk of the state's forest cover, over 77 per cent of its geographical area is arid or semi-arid. Much of this is concentrated in North Karnataka. Karnataka is also the third most urbanized state in the country and water availability is a major concern. In terms of its economy, over 50 per cent of the state's Gross State Domestic Product comes from the services sector. There has, however, been a dip in manufacturing and a reduction in mining and quarrying operations. Much of Karnataka's environmental legacy revolves around two issues; industrial activity in the Ghats in the form of paper mills, gold and iron mining, and hydro power generation; and the supply and usage of water. A related concern is the sharp disappearance of lakes and water bodies, owing to encroachment, pollution and infrastructural activity in the state. Karnataka has a number of prominent scientific and research based institutions based in its capital city Bengaluru (formerly Bangalore) and this has played an important part in the framing and content of Karnataka's SAPCC. As a progressive state, Karnataka envisions job oriented, inclusive economic growth. This will require sustainable industrialization and livelihood diversification. However, such a transition is likely to increase the demand for resources and energy significantly. Additionally, the state's dwindling resources and increasing vulnerability to climate change may threaten the achievement of inclusive growth.

Karnataka Vision 2020 policy and State Action Plan on Climate Change (SAPCC) recognize the need for climate resilience and adaptive capacity of its people and considers 'sustainability of the state's environment and natural resources' as one of the primary approaches to 'job oriented inclusive economic growth'. Thus, they should focus on green growth. The World Bank defines green growth as growth that is efficient, clean, and resilient-efficient in its use of natural resources, clean in that it minimizes pollution and environmental impacts, and resilient in that it accounts for natural hazards and the role of environmental management and natural capital in preventing physical disasters.

Karnataka's State Action Plan on Climate Change (SAPCC) identified several opportunities for the state to mitigate climate change. Under the Green Economy Strategy, the report identified key green growth opportunities for the state based on:

1) Relevance and feasibility for implementation in the state,
2) Potential to reduce GHG emissions, and

3) Fulfil the state's vision for sustainable growth.

Based on this classification, the report focused on buildings, agriculture, industries, transport, and power supply - sectors which account for all the energy requirement of the state and over $70 \%$ of the state's 2010 GHG emissions. Further, the ability of these key opportunities to meet multiple green growth objectives over the long term was considered in order to arrive at a prioritized set of relevant interventions that can be taken up by the state in the short-term.

\section{Objectives of the Study}

1. To understand the impact of climate change on various sectors in the state of Karnataka

2. To analyze the framework of mitigation and adaptation activities undertaken by the state

\section{Emissions GHG: Sector wise}

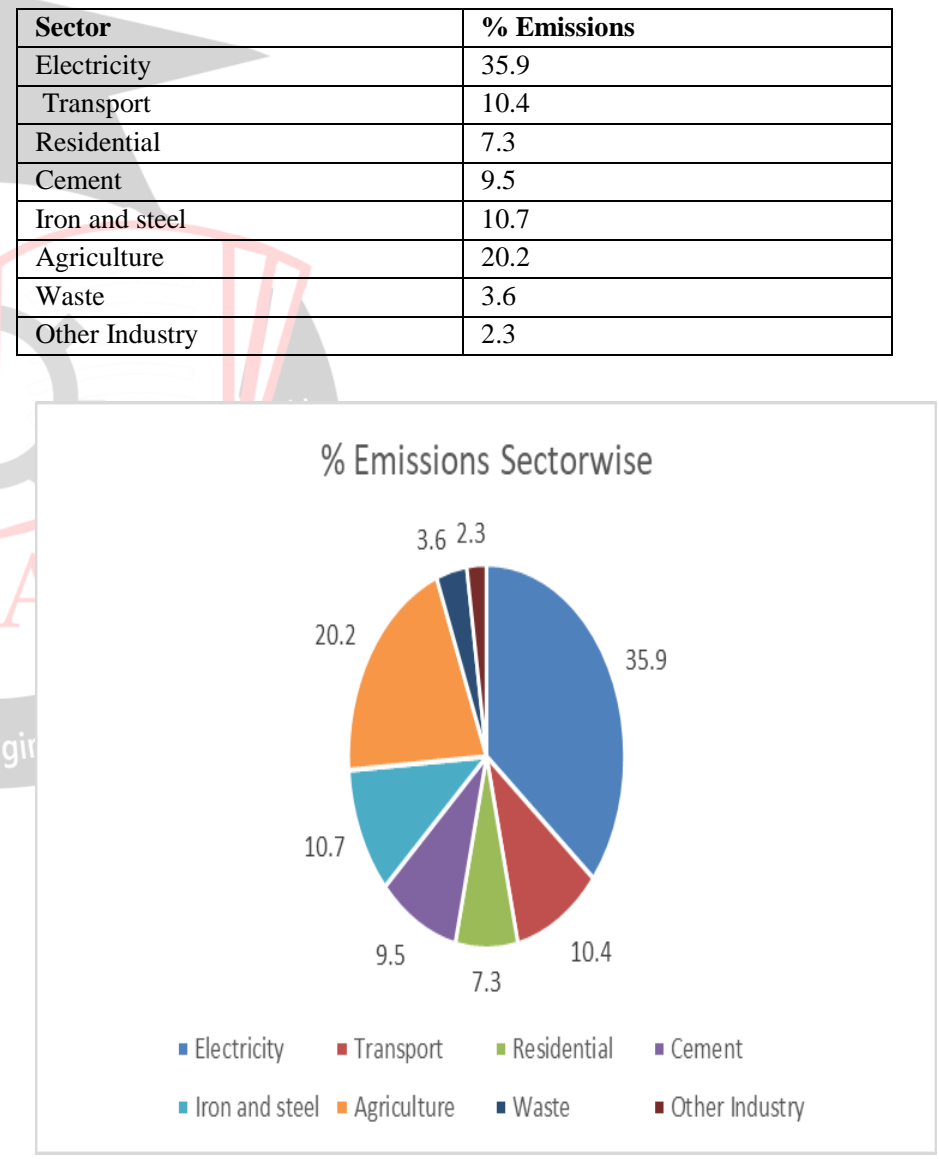

Based on the above data two major sectors contributing for GHGs emissions is considered for the study i.e. Energy and Agriculture sector.

\section{ENERGY SECTOR}

Karnataka requires about 185 million units of electricity a day, but only 135 million units are now available. The demand-supply situation has been made worse by the drought-like conditions in the state owing to a weak monsoon. Nearly 40 per cent of Karnataka's power 
generation comes from hydro-electric power plants. However, the water level at most of its reservoirs is at half of the optimum capacity, prompting the state to declare the crisis as the worst in over four decades. It is during this time when the state was facing a power crunch, more demand when compared to supply, the state was looking for an alternate option. An option which has the least gestation period. What could fit better than the Solar Energy!

Karnataka is now the renewable energy leader. There has been a massive push in the state to change its electricity mix, according to a study by US-based think-tank Institute for Energy Economics and Financial Analysis (IEEFA). "Recent solar tenders in Karnataka have seen near record low bids of Rs2.82-3.06 (per unit), materially below the average Rs3-5 for domestic thermal power tariffs and the Rs4-6 tariffs required for imported coal-fired power," the IEEFA said in the study. In quick time, Karnataka came out with multiple policies that encourage setting up of solar parks, pilot new technologies, and help farmers get into renewable energy generation.

Electricity demand in the state will grow four-fold by 2030 , largely driven by the increased demand from residential and commercial buildings. To meet this demand, the installed capacity in the state must increase to $40 \mathrm{GW}$ by 2030 from the current capacity of $12 \mathrm{GW}$. If ongoing efforts in renewable energy (RE) deployment are not accelerated, coal capacity of about $18 \mathrm{GW}$ would be required by 2030 , much of it using imported coal, with substantial implications for state's energy security. Electricity demand in the state can be reduced by about $20 \mathrm{TWh}$ through improved energy efficiency in buildings, industry, and agriculture. Along with other green interventions, such as aggressive reduction in T\&D losses (limited to 7\%) and increase in the share of renewable energy (to at least 30\%), coal requirement for the power sector can be reduced by 20 Mt in 2030 - nearly double the consumption by the sector in 2010 .

\section{Carbon emissions from fossil fuel based electricity} generations

\begin{tabular}{|l|l|l|l|l|}
\hline \multicolumn{5}{|l|}{ Emission (million tons CO2 } \\
\hline Sectors & $2006-2007$ & $2008-2009$ & $\begin{array}{l}2009 \\
2010^{*}\end{array}$ & $\begin{array}{c}2010 \\
2011^{*}\end{array}$ \\
\hline State coal & 10.92 & 14.63 & 16.49 & 20.21 \\
\hline State diesel & 0.54 & 0.54 & 0.54 & 0.54 \\
\hline Private coal & 1.18 & 1.18 & 3.92 & 8.54 \\
\hline Private gas & 0.78 & 0.78 & 0.78 & 0.78 \\
\hline $\begin{array}{l}\text { Private } \\
\text { diesel }\end{array}$ & 0.50 & 0.50 & 0.50 & 0.50 \\
\hline Total & 13.93 & 17.64 & 22.23 & 30.57 \\
\hline
\end{tabular}

\section{AGRICULTURE SECTOR}

Climate change and agriculture are interrelated processes, both of which take place on a global scale. Agriculture is more affected than other sectors of the economy by extreme weather events like floods, droughts, cold spells, heat waves, cyclones, typhoons, salinity intrusion and soil degradation. Indian agriculture is the one field where, most of the activities are environmentally associated. Climate change also poses formidable challenge to the development of livestock sector in India. The predicted negative impact of climate change on Indian agriculture would also adversely affect livestock production by aggravating the feed and fodder shortages. The anticipated rise in temperature between 2.3 and $4.8^{\circ} \mathrm{C}$ over the entire country together with increased precipitation resulting from climate change is likely to aggravate the heat stress in dairy animals, adversely affecting their productive and reproductive performance and reducing the total grazing area where high yielding dairy cattle can be economically reared.

Climate projections indicate that most parts of Karnataka could experience $1.5-2{ }^{\circ} \mathrm{C}$ warming relative 5 Challenges and Opportunities 18 Green Growth Strategy for Karnataka to the levels in pre-industrial period (1880s) by 2030s if emissions of GHG continue to increase. Gains in agriculture productivity are likely to be offset by losses from untimely high-intensity rainfalls, more frequent droughts. Change in rainfall patterns (declining Kharif season rainfall and increasing Rabi and summer season rainfall) can adversely impact Kharif/Rabi sowing time and lead to pest-disease outbreaks, bringing down the grain yields.

A possible increase in frequency and severity of droughts, with variance in rainfall will deplete the groundwater table and intensify energy demand for pumping. Demand for electricity for irrigation pumping is expected to double and reach $21 \mathrm{tWh}$ in 2030, with a subsidy bill of over INR 100 billion per year in 2030. Diesel consumption of tractors and farm machinery may cross 1.2 Mt by 2030 pushing the fossil fuel subsidy envelope to INR 22 billion.

Options identified to adapt and realize the benefits of green growth include: promoting water and nutrient use efficiency through fertigation, crop diversification using integrated farming models, packaging agro-met advisories with farm extension services, soil-fertility management and appropriate crop insurance models. The study found that increased efficiencies in fertilizer use can help save on operational costs $(20-25 \%)$ and increase fertilizer availability to crops by $25-30 \%$ and accrue savings to the tune of INR 7-9 billion/year in fertilizer subsidies. 
GHG Emissions from Agriculture Sector

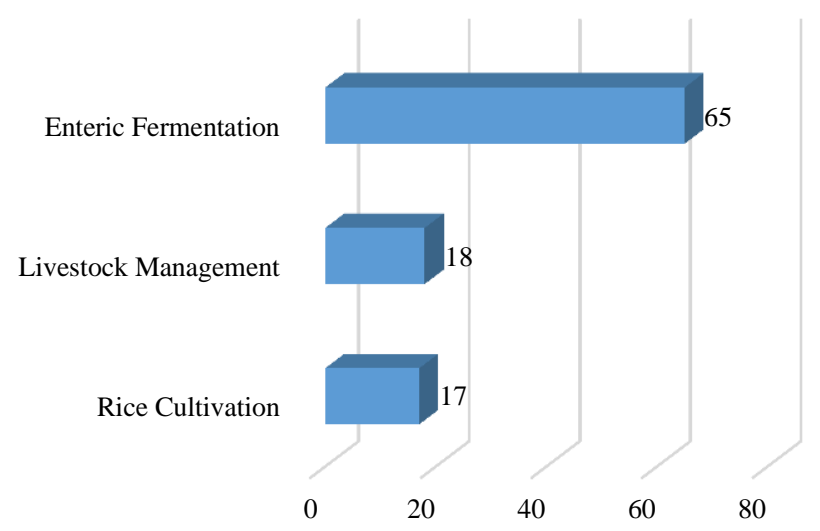

VI. ENVIRONMENT IMPACT

By 2030, just about $22 \mathrm{kt}$ for each day of city strong waste (MSW) will be produced, requiring 130 ha of land (72 ha in Bengaluru alone). Water and land debasement due to siphoning of harmful misuse (of high natural and dampness content) will be a significant ecological concern. Isolation and interchange treatment of MSW can diminish the measure of landfill squander considerably, land prerequisite by 100 ha, and methane outflows by $40 \%$.

Rising energy demand combined with expanding portion of coal will bring about a four-overlay increment in GHG outflows to around $307 \mathrm{MtCO} 2$ e by 2030 . Air quality is likewise liable to compound throughout the following decade, especially in Bengaluru. By 2020 yearly PM and NOx discharges from transport in Karnataka will increment by half to around $18 \mathrm{kt}$ and $175 \mathrm{kt}$ separately. Every single green mediation taken together can diminish $\mathrm{CO} 2$ e emanations by $30 \%$ and PM10 outflows by $40 \%$ in 2030 . Yearly SOx outflows in the force division can be cut by $34 \%$, and petroleum product reliance diminished by $22 \%$.

\section{ANALYSIS}

The entire set of green growth interventions, both for mitigation and adaptation, considered in this analysis yield significant benefits and are important to ensure Karnataka's green growth transition. However, in order to present an implementation roadmap and initiate requisite and timely policy action, key opportunities have been prioritized into 4 different categories, based on their financial attractivess/implementability, quantum of green growth benefits, and policy relevance.

General energy efficiency measures in industries, T\&D loss reduction, and intensification of public transport emerge as opportunities that have relatively high green growth benefits and are financially more attractive. Hence, these merit immediate attention to ensure that their benefits may be captured without significant economic burden. The current policy progress on these opportunities has been limited. State programs have focused on pilots or broad- based measures, but a clear policy roadmap or support for $\mathrm{T} \& \mathrm{D}$ loss reduction or energy efficiency measures in industries, especially MSMEs, is lacking. In order to realise the benefits of enhanced public transport system, considerable effort is needed to expand the existing bus fleet and the metro network in a timely manner, along with better inter-modal integration.

A robust financing ecosystem is critical for sustained pursuit of these green growth opportunities. The three key drivers for green growth deployment are policies with state government budgetary support, central government aided development programs and cross border climate finance. These drivers create an enabling environment for private sector participation in green growth opportunities. Global climate finance for 2013 has been pegged at USD 354 billion (CPI, 2013). This is significant but insufficient frame. Recommendations to reform administrative and institutional systems and planning processes; e.g. establishing long-term forest monitoring programs; coordination of planning activities, designing climate proofed irrigation infrastructure are examples. These opportunities score low due to perceived barriers in realizing co-benefits and low implementability. For rapid low carbon transition globally. Moreover this figure shows only marginal growth from 2012, which is a worrisome trend. Private sector and market based mechanisms have emerged as the largest source of climate finance with contribution of about $60 \%$. A stable policy with key interventions by governments is a key enabler to scale up the private sector engagement. It is important to note that over $70 \%$ of these funds have been deployed for development of renewable energy generation, primarily from solar and wind.

The Clean Development Mechanism (CDM) under the United Nations Framework Convention for Climate Change (UNFCCC) has been a key enabler in the last decade to finance green growth technologies and solutions especially in developing countries. Mitigation and adaptation are two broad areas of intervention considered in this report. Mitigation accounts for over $94 \%$ of the global climate finance and almost all of the private sector contribution in climate finance. On mitigation, Karnataka has an opportunity to build on its success of adoption of renewable energy generation in the state.

Karnataka spent about INR 4,577 crores (IISc, 2014) in 2012- 13 under the government of India development programs. These programs also help improve the adaptive capacity in the state. The study reviewed thirteen programs and found that three of these could be leveraged for climate resilient development in the state.

\section{CONCLUSION}

After evaluating Karnataka's long-term sustainability challenges, there is a need to develop a green growth 
strategy for the state by identifying, assessing, and prioritizing relevant and feasible opportunities. In this context, in addition to the government spending, the role of the private sector (both domestic and international) and development institutions is critical. The state government already has several progressive policies and with some additional measures in identified sectors and opportunities, the investment flows could be even faster. This would substantially reduce the risk perception of the financial institutions and expedite investment. Undertaking pilot projects in the key opportunity areas will be an important step to evaluate the strategies before they are scaled up for implementation at the state level.

- An inter-departmental Green Growth Task Force is envisioned to be the working committee that will assess the outcomes of pilots, providing inputs to development of green growth plans and overseeing their implementation. The Task Force will ensure that the state delivers on green growth goals that are aligned with its vision. Enhancing technical, institutional and coordination capacity at various levels of the government is very crucial for the design and implementation of green growth plans. In addition, academic and research institutions, non-profit organizations and the private sector in the state will also have a direct role to support the implementation of state's green growth plans and hence their capacities will have to be augmented as well. Moreover, it is important to identify gaps in exiting policies and suggest new policy measures to enable implementation.

\section{BIBLIOGRAPHY}

[1] Parikh, J., Panda, M., Ganesh-Kumar, A., \&amp; Singh, V. (2009). CO2 emissions structure of Indian economy. Energy, 34(8), 1024-1031.

[2] Dinar, A., Mendelsohn, R., Evenson, R., Parikh, J., Sanghi, A., Kumar, K., ... \&amp; Lonergan, S. (1998). Measuring the impact of climate change on Indian agriculture. The World Bank.

[3] Gupta, S., Sen, P., \& Srinivasan, S. (2014). Impact of climate change on the Indian economy: Evidence from food grain yields. Climate Change Economics, 5(02), 1450001.

[4] Boutabba, M. A. (2014). The impact of financial development, income, energy and trade on carbon emissions: evidence from the Indian economy. Economic Modelling, 40, 33-41.

[5] Aggarwal, P. K., Singh, A. K., Samra, J. S., Singh, G., Gogoi, A. K., Rao, G. G. S. N., \&amp; Ramakrishna, Y. S. (2009). Global climate change and Indian agriculture. Indian Council of Agricultural Research, New Delhi.

Web links::

https://gggi.org/site/assets/uploads/2017/11/2014-12-Green-

Growth-Strategy-for-Karnataka.pdf
http://www.nicra-icar.in/nicrarevised/images/State $\% 20$ Action \%20Plan/Karnataka\%20SAPCC\%20draft\%20-

\section{\%20EMPRI,\%20TERI\%202011-09-17.pdf}

https://www.thehindu.com/news/national/karnataka/\%E2\% 80\%98Climate-change-a-threat-to-agriculturalproductivity\%E2\%80\%99/article13983425.ece

http://www.cstep.in/drupal/sites/default/files/2019-

01/CSTEP_RR_Transitioning_Towards_a_Green_Econom y_in_Karnataka_2014.pdf

https://www.business-standard.com/article/economypolicy/karnataka-s-power-problems-get-worse115092801288_1.html 